\title{
Determinando os zeros de uma função: uma intervenção na educação básica $^{1}$
}

\author{
Helen Maria Pedrosa de Oliveira** Andréa Cardoso \\ Instituto de Ciências Exatas, UNIFAL - MG \\ 37130-000, Alfenas, MG \\ E-mail: helen.pedrosa@yahoo.com.br
}

\begin{abstract}
RESUMO
Dentre tantos conceitos abordados no ensino médio o conteúdo de funções recebe destaque por estar inserido implícita ou explicitamente em todos os anos do ensino médio e ser um dos pilares para as disciplinas de cursos de graduação, principalmente na área de ciências exatas [2]. Entretanto, tal conhecimento não é, e não deve ser, justificado apenas por seu uso em instâncias superiores de ensino. $\mathrm{O}$ conceito de função e funcionalidade não fica restrito apenas à própria Matemática. As habilidades desenvolvidas com o estudo deste conteúdo podem auxiliar na construção de modelos para diversas situações da vida real, contribuindo assim, para a formação e inserção do cidadão na sociedade. Porém, alguns tópicos deixam de ser abordados no currículo escolar da educação básica devido à sua complexidade, falta de tempo e de preparação do profissional para explorá-la. Com relação ao conteúdo de funções, o currículo limita-se ao estudo dos zeros das funções provenientes de polinômios com ordem menor ou igual a dois, como se não fosse possível determinar os zeros das demais funções polinomiais. Estes tópicos, muitas vezes, são abordados somente em cursos de graduação, como na disciplina cálculo numérico, que de acordo com [1], compreende na análise dos processos que resolvem problemas matemáticos por meio de operações aritméticas.

O cálculo numérico explora de diversos métodos para determinação de zeros de qualquer função real contínua. Mas este trabalho visa responder se é possível fazer uma transposição didática do método numérico da bissecção para o estudo dos zeros de funções polinomiais para o Ensino Médio, procurando minimizar esta lacuna que tem se perpetuado na educação básica.

Deste modo, o objetivo deste trabalho é apresentar uma sequência didática para o estudo de zeros de funções polinomiais utilizando o método numérico da bissecção, aliados a recursos como a calculadora e o computador.

A sequência didática foi aplicada a 35 estudantes do terceiro ano do Ensino Médio de uma escola pública do município de Alfenas, composta por 35 alunos e teve duração de sete aulas de 50 minutos cada. Primeiramente, foi elaborado e distribuídos aos estudantes um caderno de acompanhamento como material de apoio contendo definições, exemplos, questões e tabelas. Além disso, o caderno de acompanhamento foi um instrumento de coleta de dados. Os recursos utilizados tinham finalidades distintas. A calculadora foi um instrumento útil para a realização dos cálculos, verificação dos resultados e correção dos erros, uma vez que os alunos ganham tempo na execução dos cálculos. Por sua vez, o computador com a utilização de planilhas eletrônicas assumiu a função de validação e garantia de precisão, já que executa os cálculos com a rapidez e eficiência que o ser humano não possui.

Assim a atividade foi desenvolvida em duas etapas: investigação e método da bissecção. A etapa da investigação teve como finalidade averiguar os conhecimentos prévios que os aprendizes possuíam sobre o conteúdo de função afim e quadrática, principalmente com relação à determinação dos zeros e esboço do gráfico, para que os alunos investigassem que o zero da função é o ponto onde o gráfico intercepta o eixo das abscissas no plano cartesiano e, além disso, buscassem estabelecer a relação entre a ordem do polinômio e o número máximo de zeros que a função polinomial possui.
\end{abstract}

\footnotetext{
${ }^{1} \mathrm{O}$ presente trabalho foi realizado com apoio financeiro da Fundação de Amparo a Pesquisa do Estado de Minas Gerais (FAPEMIG) e do Programa Institucional de Bolsa de Iniciação à Docência (PIBID), da Coordenação de Aperfeiçoamento de Pessoal de Nível Superior (CAPES), Brasil.

** Bolsista de Iniciação à Docência PIBID/CAPES.
} 
A segunda etapa se caracterizou pela introdução do método numérico da bissecção para determinação dos zeros de uma função real de variável real. Nesta etapa foram propostas atividades de investigação de funções polinomiais estimulando os aprendizes a investigar um método apropriado que pudesse determinar os zeros da função, visto que utilizar de fórmulas prontas não resolveria o problema proposto. Para tentar resolver o problema, primeiramente os estudantes plotavam vários pontos no plano cartesiano e traçavam o gráfico da função dada. Depois da construção do gráfico, foi utilizada uma tabela para definir intuitivamente o método da bissecção, determinando intervalos cada vez menores que contivessem o zero da função. Para a confirmação dos valores encontrados na tabela foi utilizada uma planilha eletrônica, que apresenta resultados muito mais precisos e com erros cada vez menores, o que seria inviável caso feito manualmente. Para finalizar o processo, foi feita a definição do método da bissecção com uma linguagem adequada ao nível de conhecimento dos aprendizes, e posteriormente, foram aplicados alguns exercícios para que estes pudessem exercitar e dar indicadores de aprendizagem.

A análise dos dados mostrou que, embora o conteúdo de função afim e quadrática seja visto ao longo de todo ensino médio, muitos alunos possuem dificuldades em conceitos fundamentais, principalmente na representação gráfica, visto que mais de $60 \%$ deles não conseguem esboçar corretamente o gráfico da função plotando somente alguns pontos no plano cartesiano. Também constatou-se que a atividade proposta não foi suficiente para que os alunos estabelecessem conexões entre a ordem do polinômio do qual a função derivava e o número máximo de zeros que esta poderia ter.

Antes de introduzir o método da Bissecção, foi perguntado aos aprendizes como encontrariam os zeros de uma função de ordem três e nenhum deles apresentou uma resposta concreta. A maioria relatou não saber fazer, o que era esperado, já que no ensino médio os professores se restringem às funções polinomiais de ordem menor ou igual a dois, como se não houvesse resposta plausível para as demais.

Quando aplicado o método da bissecção, os aprendizes corresponderam positivamente às expectativas, e através da análise dos dados e da fala dos mesmos, notou-se que houve compreensão do método, já que eles pediam para reduzir o intervalo que contivera o zero da função cada vez mais, de modo que este se aproximasse do zero real da mesma. Quando questionados se a resposta encontrada era exata, os alunos ponderaram dizendo que o método resultava em uma aproximação, mas quando maior o número de iterações, esta ia se aproximando do real valor do zero da função.

Os métodos numéricos são fundamentais para a determinação dos zeros da função de ordem maior que dois. Mesmo que isto seja feito primeiramente de modo intuitivo, esta é uma ferramenta que pode ser utilizada também na educação básica, como complementação as atividades propostas no currículo do Ensino Médio.

De maneira geral, constatou-se que o cálculo numérico pode contribuir consideravelmente para o estudo de funções, já que os alunos apresentaram resultados satisfatórios durante a resolução dos problemas propostos, quando utilizaram dos métodos numéricos.

Como profissional em formação, a disciplina de cálculo numérico se mostrou pertinente na determinação de zeros de função, principalmente por seu potencial na resolução de problemas reais que sejam modelados por funções polinomiais.

Palavras-chave: Funções, método da bissecção, ensino médio.

\section{Referências}

[1] W. W. M. Lira, “Apostila de Cálculo Numérico”. pp. 1-67, 2010.

[2] H. M. P. Oliveira; A. Cardoso. "Funções Trigonométricas: criação e avaliação de objetos de aprendizagem", Trabalho de Conclusão de Curso, ICEX - UNIFAL- MG, 2014. 